\title{
LA SOCIEDAD ESTAMENTAL EN LAS OBRAS DE DON JUAN MANUEL
}

En el presente trabajo tomamos la obra literaria de Don Juan Manuel (1282-1348) como fuente para el conocimiento de la estructura social de la baja Edad Media, principalmente en su aspecto teórico ${ }^{1}$. Tienen para nosotros especial importancia el Libro del cavallero et del escudero (1326) y el Libro de los estados (1328-1330) ${ }^{2}$. En ambos se nos presentan las ideas comunes al mundo cristiano de la época sobre la estructura y ética sociales, y asimismo se reflejan algunas características peculiares de la sociedad castellana del tiempo, vista por un hombre que a la sabiduría de las capas cultas de su época unía la experiencia de su activa vida política. Sin entrar, por el momento, en el contenido de estas dos obras, queremos señalar aquí sus aspectos esenciales.

El primero de los libros es un tratado de ética y de formación caballeresca, tema, como es sabido, de primera importancia dentro de una sociedad en la que el caballero es el defensor de la comunidad, de la fe y de las personas indefensas, ya que el poder público era todavía débil para tomar a su cargo dichos cometidos; esa importancia se acrece en cuanto se considera que la ética del caballero es de superior rango, como todavía lo muestra el lenguaje actual al calificar a una persona de caballero o al hablar de una conducta caballeresca. El segundo, mucho más amplio que el primero, está dedicado - aunque no como fin de la obra ${ }^{3}$ - a los estamentos socia-

1 Ejemplos de obras en que se toma la Iiteratura como espejo de la realidad social son, entre otras, la de LÉon Gautier, La chevalerie, Paris, 1959, y las de Ricardo del Arco y Garay, La sociedad española en las obras dramáticas de Lope de Vega, Madrid, 1942, y La sociedad española en las obras de Cervantes, Madrid, 1951 .

2 Para el Libro del cavallero et del escudero seguimos la ed. de J. M. Castro y Calvo y M. de Riquer (Obras de Don Juan Manuel, t. 1, Barcelona, 1955); para el Libro de los estados, la de P. de Gayangos $\left(B A E\right.$, t. $\left.5^{1}\right)$, en la cual hemos introducido las restauraciones ortográficas más obvias e indispensables (dezir, fazer, dexar, etc., en vez de decir, facer, dejar). Abreviaremos respectivamente Cav. y Est., y remitiremos en cada caso al capitulo de la obra.

3 En el pensamiento del autor, el fin de esta obra es dar a conocer los diferentes estados sociales del hombre como medio para saber en cuál de ellos es más fácil salvar el alma. Sin embargo, aunque esto sea lo primordial, pasa en realidad a segundo término, y cobra relieve el aspecto socio-político del tema. 
les, y, hasta donde sabemos, es el único tratado de la baja Edad Media destinado específicamente a estudiar la estructura social ${ }^{4}$, para lo cual utiliza el autor un esquema teórico común al Occidente europeo de la época, aunque, dentro de este esquema común, expresión de la unidad cultural del Medioevo, se muestran esos matices específicos que son los que van conformando y diferenciando un pueblo de otro en el camino hacia su individualización.

Como ha demostrado Sánchez Albornoz, la invasión musulmana y la subsiguiente reconquista y colonización impidieron en España (con excepción de Cataluña) el desarrollo de un feudalismo organizado, y las clases sociales se constituyeron sobre bases bastante diferentes de las del resto de Europa. Podemos afirmar que Don Juan Manuel, aun conociendo y manejando los conceptos de la teoría social generales de su tiempo, tiene presente aquí -como en toda su obra- la realidad hispánica, del mismo modo que vio también desde la perspectiva española el problema del Imperio ${ }^{5}$.

La estructura social a la que nos referimos se denomina en la sociología moderna "sociedad estamental", diferente tanto de nuestra sociedad de clases como de la de castas $^{6}$. Esa sociedad es la que impera en la Edad Media, y es su teoría la que utilizaremos como esquema básico para interpretar los textos de Don Juan Manuel.

\section{LA SOCIEDAD MEDIEVAL}

\section{EsTADo Y ESTAMENTo}

El término estado es lo castellano, y es más usual que estamento (del catalán estament 'manera o forma de estar', 'condición social'). Es lo general también en las demás lenguas europeas: francés (état), anglo-normando (state-estate), italiano (stato). En Cerdeña la forma stamento se debe a influencia aragonesa. En la lengua alemana penetran en el siglo xiv Stand, Stant ${ }^{7}$. Todas estas formas derivan de

4 Son muy frecuentes las alusiones a la sociedad estamental en obras de política, teología, espejos de principes, etc., pero fuera de la de Don Juan Manuel no conocemos ninguna destinada de modo exclusivo a estudiar la estructura estamental. Por lo menos, no la hemos encontrado en el catálogo de W. BERGES, Die Fürstenspiegel des hohen und späten Mittelalters, Stuttgart, 1952, ni en otros libros sobre historia de las ideas políticas durante la Edad Media.

5 Cf. Manuel Torres, "La idea del Imperio en el Libro de los estados de Don Juan Manuel”, Cruz y Raya, 15 de mayo de 1933, pp. 61-9o.

6 Véanse Hans FreYer, Introducción a la sociologia, Madrid, 1951, pp. 153157; In., La sociologia, ciencia de la realidad, Buenos Aires, 1944, pp. 297-310; Max Weber, Economia y sociedad, México, 1944, t. 4, pp. 54-71; MaNuel García-Pelayo, La constitución estamental. (Agradezco al profesor García-Pelayo que haya puesto a mi disposición este estudio, aún inédito, asi como la valiosa ayuda que me ha prestado en la elaboración de mi trabajo).

7 E. Lousse, La société d'ancien régime, Paris, 1943, p. 250; Y. JAck und W. Grrmm, Deutsches Wörterbuch, X:2, Abt. $68_{3}$ ss. Véanse también W. 
la latina status (stare), y la unidad en la terminología indica la profunda identidad de pensamiento de la época. Los significados son siempre dos: a) situación general, circunstancia; b) uno de los grupos o rangos en el orden de la vida social.

Don Juan Manuel utiliza la forma castellana estado en las dos significaciones antedichas. En un sentido que podemos llamar subjetivo, y más cercano a la etimología latina, con el valor de circunstancia', 'modo de estar', 'situación': “. . .la primera cosa que yo entiendo que vós devedes fazer para salvar el alma et ponerla en buen estado, es que ayades ley en que creades" (Est., 23); “...el estado de este mundo... es estado fallecedero et que ha de durar poco a comparación del duramiento del alma" (Est., 47).

Desde un punto de vista objetivo y específicamente social, Don Juan Manuel emplea la palabra para designar los grupos sociales básicos de la sociedad, dotados de análoga situación y de unos mismos privilegios, o bien formas particulares, rangos o (más precisamente) "dignidades" dentro de un determinado grupo social, como "estado de duque" o "estado de emperador".

\section{ORDENACIÓN DE LA SOCIEDAD MEDIEVAL}

El concepto de "estado" o "estamento" fue el que sirvió de ordenador para la sociedad medieval, de la misma manera que el de "clase" o "grupo socio-económico" lo son para nuestra sociedad, o el de "casta" para algunas sociedades del presente o del pasado. Pero aun partiendo del empleo general del concepto estamento para mostrar la estructura horizontal y vertical de la sociedad, tal concepto podía emplearse con sentido y amplitud distinta, y dividirse la sociedad en tantos estamentos como dignidades, grupos, situaciones y oficios había. Así, por ejemplo, en una poesía satírica de la primera mitad del siglo xv se enumeran más de cincuenta estamentos (Stände) en la forma más heterogénea: el Papa, el Emperador, las monjas, los asesinos, los bufones, los mendigos, etc. ${ }^{8}$, con un criterio completamente empírico y asistemático.

Mucho más extendida, clara y sistemática era la división de la sociedad en tres estados o estamentos. El primer documento que testimonia esa división es del siglo Ix (Les miracles de saint Bertin). Se

Schwer, Stand und Standesordnung im Weltbild des Mittelalters, Paderborn, 1952, p. 1, y A. Marongru, L'istituto parlamentare in Italia, Roma, 1948, pp. 167 y 198. Cf. Partidas, IV, xxır, 4: "Status hominum tanto quiere dezir en romance como el estado o la condición o la manera en que los homes viven o están..."

8 Des Teufels Netz, cit. por Otto Brunner, Land und Herrschaft, Wien, 1959, p. 40o. En un documento de la historia constitucional inglesa, el Modus tenendi Parliamentum (comienzos del siglo xrv), se habla de los seis "grados" que constituyen el Parlamento; el primer gradus (= estado) está formado únicamente por el Rey. 
distinguen allí tres grupos: oratores, bellatores e imbelle vulgus, denominaciones que reaparecen en un texto anglosajón del siglo siguiente y que se generalizarán durante toda la Edad Media en el mundo occidental cristiano, si bien la denominación de imbelle vulgus es reemplazada por la de laboratores ${ }^{9}$. Teniendo en cuenta la unidad cultural del Medioevo, no nos debe extrañar que la misma ordenación sea también la vigente en la España cristiana, y así Don Juan Manuel, en el Libro de los estados, dice que "todos los estados del mundo... se encierran en tres: al uno llaman defensores, et al otro oradores, et al otro labradores" $\left(9^{2}\right)^{10}$. Cada grupo social o estado se caracteriza por la unidad entre la condición social y el status jurídico, a diferencia de nuestra sociedad, que tiene por principio la igualdad de todos ante la ley, aunque esta igualdad sea compatible con las diferencias de condición social. En la Edad Media la condición social y el status jurídico tienden a unificarse: el derecho es creado en su mayor parte por la sociedad misma, a través del uso o de la costumbre o de la conversión en jurídicas de situaciones fácticas de poder. En virtud de esas normas, la sociedad se estructura en un sistema de "privilegios", los cuales no se entienden, según veremos después, en el sentido de una situación jurídica simple-

9 Cf. E. Lousse, op. cit., p. 103 .

10 El lat. orare, que significaba 'hablar' y también 'pronunciar una fórmula jurídica o religiosa', se llenó de contenido cristiano-religioso, aplicándose exclusivamente al acto de elevar una plegaria o de dirigirse a la divinidad. Es natural que también orator tomara en el latín eclesiástico valores específicamente religiosos, pasando a significar 'el que ora', y más en concreto 'el sacerdote'. Este uso se halla documentado desde el siglo v. He aquí algunos ejemplos que tomamos del Glossarium de Du Cange: "Deus tribuat, ut qui fuerunt discipuli quondam mei, sint nunc quotidie oratores mei" (Salviano [ca. 428], Epist., 8); "Notum sit pietati vestrae quia in quantum Deus nos exaudire dignatur, oratores vestri incessanter sumus" (San Bonifacio [680-755], Epist., 113); "Orator Christum rogat" (Juan de Garlandia [ca. 1040]); "Genus humanum ab initio trifariam divisum esse monstravit, in oratoribus, agricultoribus, pugnatoribus... Oratorum a saeculi vacans negotiis, dum ad Deum vadit intentio..." (Baldrico [ca. 1112], Chronicon Cameracense, lib. 3, cap. 52). - Con este sentido pasó a las lenguas romances (cf. Dante, Paradiso, 3o, v. 41), y así se encuentra en Elena y Maria, poema del siglo xIrr (ed. de R. Menéndez Pidal en RFE, 1, 1914, p. 56): "Somos hermanas et fijas de algo / mays yo amo al mays alto, / ca es cauallero armado, / de sus armas esforçado; / el mío es defensor, / el tuyo es orador..."; y luego en las Partidas de Alfonso el Sabio (II, xxI, proemio), antecedente inmediato del pasaje de Don Juan Manuel: "Defensores son uno de los tres estados por que Dios quiso que se mantuviese el mundo; ca bien así como los que ruegan a Dios por el pueblo son dichos oradores..., otrosí los que labran la tierra... son dichos labradores". En otro texto de Don Juan Manuel se reafirma ese mismo valor: "Como quier que el estado de los que llaman labradores non es tan alto ni tan honrado como el de los oradores, pero porque vós sodes lego, et los deste estado son legos, dezirvos he primeramente lo que entiendo en los estados que se encierran en el estado de los labradores, et después fablarvos he en los estados que se encierran en el estado de los oradores" (Est., 93); y persiste todavia en el Victorial de Gutierre Díez de Gámez 
mente ventajosa, sino en su valor primario (privi-leges), es decir, como derechos o libertades ${ }^{11}$ privativos o particulares de cada grupo o persona-concepción del derecho completamente opuesta a la igualdad y homogeneidad de nuestros actuales ordenamientos jurídicos. En general, la teoría política de la Edad Media sostenía que el poder político estaba obligado a conservar y garantizar los privilegios. Así dice Don Juan Manuel que el señor ha de proteger a sus naturales, y "dévese guardar de les non quebrantar nin les menguar fueros, nin lees et privilejos et buenos usos et buenas costumbres que han" (Est., 87).

Estos "privilegios" podían ser producto del reconocimiento jurídico de situaciones de hecho, o del otorgamiento de una autoridad superior: "el rey... deve fazer et guardar tres cosas: la primera, guardar las leyes et fueros que los otros buenos reyes que fueron ante que él dexaron a los de las tierras, et do non las fallare fechas, fazerlas él buenas et derechas..." (Cav., 3).

Pertenecer a un estamento implicaba la posesión de ciertos derechos - privilegios- diferentes de los de otros, y, paralelamente, ciertas obligaciones. Es de gran importancia apuntar esta correlación entre privilegio y deber, de donde deriva el dicho noblesse oblige. Es una característica esencial de la sociedad estamental en los momentos de su florecimiento, aunque más tarde, en el período de su decadencia, los altos estamentos sólo se acuerdan de las ventajas de sus privilegios y olvidan los deberes correlativos. La correlación o justificación del privilegio por el servicio obligaba a los miembros de los altos estamentos a la realización de obras que justificaran su rango. El ser noble suponía, más que derechos, obligaciones; la (1978-1448), que es no sólo una biografía de Don Pero Niño, sino también un código caballeresco: “...por disposición de la potencia divina, que le plugo ansí de ordenar el mundo, que oviese tres estados de gentes: oradores e defensores e labradores" (proemio). - Este uso no pasó de la terminología eclesiásticopolítica, a pesar del texto de Elena y Maria, ejercicio poético sin duda de un clérigo más erudito de lo que se cree. De otro modo no se explicaria el sentido de 'decidor, chistoso' que tiene en Berceo (Santo Domingo, 326). Con el humanismo se desvaneció totalmente la acepción medieval, que ni siquiera se encuentra registrada en los léxicos españoles, y se restableció la acepción clásica. Desde el siglo xv alterna con ésta la acepción de 'embajador', que penetra con la influencia italiana, y que se halla documentada en Torres Naharro, Juan de Mena, el Marqués de Santillana y Castillejo (Propalladia, ed. Gillet, t. 3, pp. 97-98; María Rosa LIdA de Malkiel, Juan de Mena, poeta del Prerrenacimiento español, México, 1950, p. 253).

11 Es de notar que para la Edad Media no existe un concepto ábstracto y objetivo de libertad, sino subjetivo e individual, y referido a las personas físicas lo mismo que a las corporaciones y dignidades e incluso a las cosas; se habla asi de las "libertades que han las iglesias", la "libertad de la heredat" (Est., 61), etc. Cf. G. Tellenbach, Church, State, and Christian society, Oxford, 1948, p. 21: "A privilege does not create exceptions to a generally prevailing law; rather it is the precise formulation of an actual and concrete subjective right, that is, of a libertas". 
nobleza de estirpe se sustentaba en las obras, y así en el Victorial se dice que es "hijo de ninguno" aquel que no mantiene en su integridad su linaje. Del mismo modo Don Juan Manuel critica la actitud de gente de linaje que no cumple esta máxima: “ca cierto creed que en mal punto fue nascido el t.ome que quiso valer más por las obras de su linaje que por las suyas" (Est., 85). Y al referirse a la antigua costumbre de que antes de ser coronado el emperador elegido debía cercar durante cuarenta días un castillo y luego otro, muestra la importancia que tenía la justificación del propio cargo y la correlación entre privilegio y deber. De este modo - dice Don Juan Manuel- podía probar el elegido que estaba a la altura del oficio que iba a desempeñar. Como observa Ortega y Gasset, para los hombres de la Edad Media "son una misma cosa tener un derecho y ser capaz de sustentarlo" (Obras completas, t. 2, p. 423). En una comparación poética Don Juan Manuel pone de manifiesto esta jerarquía entre el rango y la obligación: "que bien así como una manziella parescía muy peor en un paño muy presciado que en otro muy feo et muy vil, que bien así quanto el señor es de mayor estado et deve fazer siempre mayores fechos et dar de sí mayores,enxiemplos a las gentes, parescía muy peor et faría mayor maldat en fazer cada una destas cosas contra el su natural que el que éste las fiziese contra él"' (Est., 87).

Con la misma fuerza que una ley moral y como una faceta de su honra, era sentida en la conciencia de los pertenecientes a los estados superiores la unidad de privilegio y servicio. Desde el momento en que se pierde esta unidad comienzan a romperse las bases de la sociedad estamental, pues, como ha señalado Freyer, la conciencia de estamento era mantenida por los grupos superiores, mientras que en la sociedad de clases la conciencia de clase es mantenida, sobre todo o exclusivamente, por los estratos inferiores ${ }^{12}$.

Dado que la sociedad medieval es esencialmente teocéntrica ${ }^{13}$, se mantiene la tesis de que el origen de la separación de los hombres en grupos desiguales radica en la voluntad de Dios, en el orden de la Providencia, que asigna a cada uno su lugar en el mundo para que cumpla los fines de la Creación. El modelo de la estructura de la sociedad terrestre es el ordenamiento celeste, tal como se muestra en la obra de Dionisio el Areopagita, de modo que así como hay tres coros angélicos, así hay tres estamentos básicos en la sociedad. Es famosa a este respecto la contestación que dio Hildegarda de Bingen a los que le preguntaban por qué en su monasterio sólo podían ingresar mujeres nobles: "Dios divide a su pueblo sobre la tierra en distintas clases, como clasifica a los ángeles en diversos grupos...

12 HANs Freyer, Introd. a la sociología, pp. 154-155; La sociología, ciencia de la realidad, p. 304 .

13 Véase M. García-Pelayo, El reino de Dios, arquetipo político, Madrid, 1959, pp. 79 ss. 
Pero Dios los ama a todos por igual"14 —contestación que condensa los puntos de vista a que acabamos de referirnos.

La idea del origen divino de los estamentos aparece también en Don Juan Manuel: “. . .et por todas estas razones tengo que el estado del Emperador vos caye mucho et señaladamente, pues Dios en él vos puso" (Est., 48); “. . .yo entiendo et tengo que la bondat de Dios es tan complida, que en quanta mayor honra et en mayor estado pone a los homes en este mundo, tanto más es su voluntad de gelo mantener et acrescentar en el otro" (Est., 47); y lo repite otra vez: "...el estado en que me Dios puso" (Est., 16). También se encuentra en él una alusión al orden angélico. Aunque no se refiere directamente a la sociedad como copia del modelo celeste, la cita es interesante, porque indica la permanente presencia de la idea de la separación - de ángeles o de hombres- en grupos, primordial para el buen funcionamiento de la sociedad: "los ángeles. . . [están] puestos en órdenes, segund nuestro señor Dios tovo por bien et entendió que se podría más servir dellos" (Cav., 32).

Pero si estamos en presencia de una desigualdad social querida por la Providencia, existe también una igualdad sustancial que se basa en la común pertenencia de los hombres a la comunidad cristiana, y que impide la formación de castas. Hay, además, una igualdad sustentada en las leyes biológicas, que se manifiesta en el transcurso de la vida física y especialmente en los dos momentos límites de la vida: nacimiento y muerte: "Señor, vós me dexiestes muchas razones por que entendíades que el nascer et el crescer et el envejecer et después la muerte, que en todos los homes era egual..." (Est., 12). Por debajo de la desigualdad social se reconoce la realidad ineludible de la igualdad natural que hoy llamaríamos biológica, ya que "la razón me da que como quier que el rey mio padre et yo hayamos mayor poder et nos fagan las gentes mayor honra que a los otros, que quanto en el nacer et crecer et envejecer que iguales somos de los otros homes" (ibid.). E1 tema de la muerte como niveladora de todos los hombres va a adquirir posteriormente un alto carácter poético en el Arcipreste de Hita, en Jorge Manrique y en la Danza en que la Muerte dice:
A la dança mortal venit los nasçidos que en el mundo soes de qualquiera estado...

Este orden social se caracterizaba por la inmutabilidad, ya que era Dios quien así lo había establecido. Un cambio social iría contra los designios divinos. De ahí que durante la Edad Media toda sublevación social revistiera un carácter herético. El príncipe Johas -personaje principal del Libro de los estados-, a pesar de que quiere

14 Cit. por J. Bühler, Vida y cultura en la Edad Media, $2^{\mathrm{a}}$ ed., México, 1957, p. 104. (El texto es del siglo xn). 
conocer todos los estados que hay en el mundo para saber en cuál hay mayor posibilidad de salvación, parte del principio de que no piensa ni puede "mudar el estado en que me Dios puso" (Est., 16).

Además de recurrir al modelo celeste, la Edad Media acude también, para la ordenación teórica de la sociedad, al principio funcionalista ya contenido en la idea paulina del cuerpo místico, y complementado en la época de Don Juan Manuel por las ideas aristotélicas. Unida a estas ideas está la concepción organicista de la sociedad como un todo único en el que cada miembro cumple una función específica, y cuyo perfecto funcionamiento depende de la ordenada distribución de las partes componentes ${ }^{15}$. La buena salud y constitución de una comunidad, partiendo del criterio funcionalista o bien del criterio teocéntrico (armonizados ambos en la idea del "cuerpo místico político" o "civil" $)^{16}$, se basaba en la división y armonía de los grupos que la constituían"

El Medioevo no podía, pues, concebir una sociedad que no estuviese estructurada en grupos desiguales por la diferente función que cumplía cada uno de ellos dentro de la comunidad. La desigualdad era condición del orden; la igualdad equivalía al caos. Por eso "los cibdadanos non deven ser iguales nin en las posesiones ni en los oficios, ca esto sería destruimiento de la cibdad e fazer que la cibdad no fuese cibdad"18. Los tres estados que presenta Don Juan Manuel responden a este criterio funcionalista y organicista común a la época, puesto que oradores son los que se dedican a la salvación de la comunidad, defensores los que la defienden por las armas y el gobierno, y labradores los que la sustentan con su trabajo. Pero la manera de constituirse y delimitarse cada uno de los estados responde a características propias de la España cristiana, como veremos más adelante.

Dentro de los tres estados hay una jerarquía, factor de suma importancia en la mentalidad del hombre medieval, que responde a la idea escolástica "del orden natural, que no sólo reúne las cosas semejantes, sino que las articula jerárquicamente según su función en un conjunto que va desde lo más perfecto a lo menos perfecto, de lo superior a lo inferior"'19. En la estructura misma de sus obras Don Juan Manuel sigue este orden, ya que comienza por hablar de los estados más altos hasta llegar a los inferiores, y de estos últimos

15 Sobre el concepto de organismo véase $\mathbf{F}$. O. von GIerke, Les théories politiques du moyen âge, Paris, 1914, pp. 135-152.

16 Véase E. Kantorowicz, The king's two bodies: A study in medieval political theology, Princeton, 1957, pp. 207 ss.

17 Georges DE LAGARDE, "Individualisme et corporatisme au moyen âge", en la colección de trabajos L'organisation corporative du moyen âge à la fin de l'ancien régime, Louvain, 1937.

18 Glosa castellana al "Regimiento de principes" de Egidio Romano, Madrid, 1947 , t. 3, p. 80.

19 M. García-Pelayo, La constitución estamental. (Cf. supra, nota 6). 
es bien poco lo que dice, seguramente por la poca dignidad que les concede. (La conciencia de estamento, como hemos dicho antes, es sentida sobre todo por los superiores). La jerarquía social que otorga un "mayor estado" y una "mayor honra" se debe al valor de la labor realizada en la comunidad, o sea que el estado asignado por Dios al hombre es otorgado como un medio para hacer el bien: "ca segunt dizen los sabios, que non deve el home desear aver grant estado por pro nin por honra de sí mesmo, mas que lo deve desear por fazer en él mucho bien" (Est., $4^{8}$ ).

\section{LOS ESTAMENTOS}

Examinados los supuestos generales de la concepción social que preside la obra de Don Juan Manuel, analizaremos ahora sus ideas sobre cada uno de los estratos o estados de que se compone la sociedad:

\section{Oradores}

El primer grado en la jerarquía social lo constituyen los oradores, es decir, los que oran, los sacerdotes: "el estado de la clerecía es el más alto estado que puede seer" (Est., $2^{\text {a }}$ parte, 3); "según el mi flaco saber, tengo que el más alto estado es el clérigo missacantano" (Cav., 17). Es ésta una idea común a todo el pensamiento social de la Edad Media, ya que está de acuerdo con la naturaleza cristocéntrica de la sociedad, orientada hacia la salvación. Pero antes de ver de qué manera se desarrolla este pensamiento en Don Juan Manuel, veamos los tipos, o más bien, los grados de sociedades que distingue.

Hay una "ley de naturaleza, que es no fazer tuerto ni mal a ninguno" (equivalente al sano instinto), a la que están sujetos los animales y los hombres, pero que cumplen mejor los animales ${ }^{20}$, pues en el hombre el instinto es desviado por "entendimiento et libre albedrío", que le ofrece la posibilidad de obrar mal. Los hombres tienen no sólo instinto, sino también "entendimiento et razón", cualidades que les permiten fundar sociedades específicamente humanas. Don Juan Manuel, de acuerdo con la corriente escolástico-aristotélica, admite la legitimidad de estas sociedades fundadas en la constitución del hombre como ser racional, o sea en la naturaleza humana: el hombre es un ser incapaz de vivir aisladamente, ya que carece de defensas adecuadas para ello, pero en cambio está dotado de razón, que le muestra la necesidad, y de lenguaje, que le abre la posibilidad de vivir en sociedad. Es, pues, inherente a la naturaleza

20 Est., 24: "et esta ley también la han las animalias como los homes, et aun mejor; ca las animalias nunca fazen mal las unas a las otras que son de su linaje, nin a otras sinon con grant menester". Las citas que siguen pertenecen a los capítulos 25 y 26 de la misma obra. 
humana la convivencia con sus semejantes. La sociedad, aun al margen de toda fundamentación religiosa, se justifica por sí misma y es capaz de conseguir un orden de paz y justicia, si bien su perfeccionamiento sólo se alcanza por la gracia, de acuerdo con el principio de Santo Tomás: gratia non tollit naturam, sed perficit ${ }^{21}$. Una de estas sociedades es el reino del príncipe Johas, en el que viven los súbditos en "ley de justicia" y que se puede considerar como una primera etapa de la sociedad, como supuesto previo para ser tocada por la gracia de la cristianización. Ahora bien, esta sociedad, aunque necesaria y legítima, sirve exclusivamente a los fines temporales del hombre.

Pero el hombre tiene además un alma inmortal que debe ser salvada, pues "de balde ovieron los homes entendimiento et razón, lo que non han las animalias; demás que los homes han alma, que es cosa spiritual que nunca ha de fallescer. .." Por consiguiente, no sólo importa la salvación temporal de esta vida, a la que sirve la sociedad política, sino que se precisa, además, la salvación espiritual y eterna, que sólo puede ser obra de una ley y de una institución eternas, pues "en ninguna ley, que sea dada, nin sea natural, non se pueden salvar las almas al tiempo de agora, sinon en la ley de los cristianos". Por tanto, la salvación sólo puede darse a través de la Ley Nueva establecida por Jesucristo, a la que se acogerá el príncipe Johas: los hombres "no pudieran ser salvos... fasta que Jesucristo vino et dio esta ley de gracia".

Veamos ahora, partiendo de estos supuestos, las razones de la preeminencia del sacerdocio. En primer lugar, recordemos que la comunidad cristiana es un "cuerpo místico" cuya cabeza es Cristo ${ }^{22}$; ahora bien, el primer sacerdote fue "nuestro señor Jesucristo. .., que fizo el sacrificio del su cuerpo et de la su sangre"; y siendo los clérigos sus continuadores, han de ocupar el lugar capital de la sociedad, puesto que prolongan su cabeza, es decir, a Cristo. En segundo lugar, el sacerdote es el único mediador entre Dios y los hombres; sólo él, con el poder de la palabra, hace "que el pan verdadero se torne carne et ... cuerpo de Jesucristo, et el vino su sangre propia", con lo que asegura la permanencia de Cristo en medio de sus fieles y el descendimiento de la gracia sobre la sociedad. Además, los hombres que componen la comunidad no pueden salvarse sino mediante la gracia operada por los sacramentos, pero el poder sacramental es

21 Véase la Introducción de A. Passerin D'Entreves a los Escritos politicos de Santo Tomás, Caracas, 1962.

22 Es más propio hablar de comunidad que de sociedad. La comunidad se estructura como un organismo cuyos componentes se consideran miembros unidos por la confianza mutua, y a ella se pertenece de un modo total y más allá de todo cálculo; ella impone su sello al conjunto de la personalidad de los miembros. Éste es el tipo de convivencia que se da en la Edad Media. Véase F. Tönnies, Comunidad y sociedad, Buenos Aires, 1947. 
exclusivo de los sacerdotes, ya que "pueden dar et dan todos los sacramentos de Sancta Eglesia, et todas estas cosas non puede fazer otro home"; por tanto, solamente en el sacerdote radica la posibilidad de salvación. La tercera razón es la militancia por la ley. El sacerdote, en efecto, debe "mantener la ley et lidiar por ella en tres maneras", la primera de las cuales es "lidiar con armas contra los moros, que son nuestros enemigos". Como antecedentes hispánicos sobre la cuestión podemos señalar que en el Poema del Cid se nos presenta Don Jerónimo, obispo de Valencia, monje francés imbuido del espíritu de las cruzadas, como "guerrero esforzado" que a la entrada del Campeador en Valencia le recibe con estas palabras (vs. 2371-3):

Por esso salí de mi tierra e vin vos buscar, por sabor que avía de algún moro matar: mi orden e mis manos querríalas ondrar.

Y en las Partidas ( $\left.1, \mathrm{vI}, 5^{2}\right)$ se establece que los clérigos deben tomar las armas cuando el enemigo sea un infiel, como es el caso de los moros; en tales circunstancias "non se deven los clérigos escusar, que non velen, e non guarden los muros... E otrosí los obispos... que tovieren la tierra del rey... deben ir en hueste con el rey" ${ }^{23}$. La segunda militancia es la lucha del sacerdote contra las potencias del mal: "con el diablo et con el mundo et consigo mismos". Y por último coloca Don Juan Manuel la defensa intelectual de la fe cristiana, que reviste dos aspectos: los sacerdotes deben mostrar a los enemigos de la ley, judíos, moros, paganos y gentiles, por medio de las Escrituras y de la razón, que la ley cristiana es la única que otorga la salvación; y a los cristianos deben "predicarles et amostrarles las maneras como pueden mejor salvar las almas et mantener sus estados"24. En una palabra, han de luchar tanto contra los enemigos visibles como contra los enemigos invisibles de la fe.

23 No caigamos en la vulgar tentación de ver en esto un hecho exclusivo de España. En el Sacro Imperio y en Francia, los obispos asumieron funciones militares a raíz de las invasiones sarracenas, normandas y húngaras (M. GarcíaPelayo, El reino de Dios, p. 114); por otra parte, el deber de tomar las armas era para los prelados una consecuencia lógica del proceso de feudalización de la Iglesia, pues al recibir el obispo una tierra como beneficio, entraba en relación de vasallaje y, por tanto, se obligaba a prestar al señor el "auxilio militar". La actividad militar de los obispos llegó a ser tan común, que el autor del tratado De unitate ecclesiae conservanda (1108), muy conocido durante la Edad Media, dice en son de crítica: "Quales scilicet episcopi non essent pastores ecclesiarum sed ductores bellorum, non custodes dominicarum ovium, sed ut graves lupi persecutores earum, interfectores animarum pariter et corporum". (Cf. todavía las palabras de Erasmo en la Querela pacis [1516], cit. por MARCEL Batalllon, Erasmo y España, México, 1950, t. 1, pp. 103-104). Cuando tratemos de los caballeros veremos cuán laxa era la separación entre la actividad guerrera y la religiosa en toda la cristiandad.

${ }^{24}$ Las citas proceden del Libro de los estados, $2^{3}$ parte, cap. 3 . 


\section{DefENSORES}

El segundo lugar lo ocupan los defensores, estamento que comprende desde el emperador al último caballero, pero que naturalmente está ordenado en distintos rangos, e incluso, como veremos más adelante, admite en su seno algunos grupos de nobleza dudosa. A su vez, dentro de un mismo rango jerárquico se dan ciertas diferencias. Así, los ricos homes, que son "los que pueden et deven traer pendones et aun cavalleros por vasallos..., non son todos de una guisa nin son eguales en linaje nin en honra nin en poder" (Est., 89); en efecto, una rama está constituida por los del linaje real, otra por los nobles "que como quier que non son del linaje de los reys, que casan los fijos et las fijas con los fijos et las fijas de los reys", y un último grupo de individuos que, siendo caballeros e infanzones por privanza de los reyes, son elevados a ricos homes, privilegio que no siempre es hereditario: Don Juan Manuel mismo ha visto "en Castiella et en Aragón pieza de ellos que fueran fechos ricos homes de los reys, que nunca sus fijos fueron tenidos por ricos homes" (ibid.).

Aun teniendo en cuenta las diferencias internas de rango, Don Juan Manuel suele emplear el término cavallero como nombre genérico para todo el estamento noble, es decir, los "nobles defensores", pero en su sentido restringido se refiere a quienes han sido investidos de caballeros, que "es la mayor honra a que home fijo dalgo puede llegar" (Est., go). En toda la sociedad medieval, el caballero ocupaba un lugar preeminente, inmediatamente después del sacerdocio, pero siempre que sirviera a los fines a que estaba ordenada la sociedad, es decir, la defensa de la fe católica, de la comunidad y de los seres que en aquel tipo de sociedad se encontraban particularmente indefensos, como las mujeres, los niños, los viajeros, etc. ${ }^{25}$ Sin duda que la vida del caballero se mostraba revestida de los más altos valores éticos, y de ahí que se convirtiera en ideal de vida y modelo de príncipes; el mismo Don Juan Manuel tenía el Libro del orde de la cavaylería de Ramón Llull como código moral: se lo hacía leer en sus tan frecuentes noches de insomnio, y además lo adoptó como modelo para componer su Libro del cavallero et del escudero ${ }^{26}$.

${ }^{25}$ Como síntesis de los deberes y de la significación de la caballería puede valer esta fórmula de juramento: "Escuchad, oh señor, nuestras plegarias y bendecid con la mano de vuestra majestad esta espada que vuestro siervo desea que le sea ceñida para poder defender y proteger las iglesias, las viudas, Ios huérfanos y todos los siervos de Dios contra la crueldad de los paganos, y a fin de ser el temor de todos aquellos que les ponen asechanzas" (cit. por G. SCHNürer, Kirche und Kultur im Mittelalter, Paderborn, 1926, t. 2, p. 271).

26 Por desgracia, parte del Libro del cavallero et del escudero (capítulos 3 a 17 ) se ha perdido, al igual que el Libro de la cavallería, citado a menudo en el Libro de los estados. 
a) La investidura

La sociedad estamental se caracterizaba por su tendencia al hermetismo, es decir, a no admitir extraños en el seno de cada estamento sino después de hacerlos pasar por determinadas pruebas o ritos de iniciación. Y así como la pertenencia al estamento de los oradores o sacerdotes tenía como requisito previo la ordenación, así no se podía pertenecer al estamento de los caballeros sin la investidura, que viene a ser un caso de lo que Max Weber llama la "rutinización del carisma".

La cristianización de la caballería, los momentos religiosos que intervenían en la ceremonia de la investidura ${ }^{27}$ y su articulación dentro de una sociedad teocéntrica, todo ello unido a la imprecisión que había en la doctrina sacramental hasta el siglo $\mathrm{xn}^{28}$, tiene como consecuencia que la investidura del caballero se considere un cuasisacramento, idea presente en Don Juan Manuel a pesar de que en su tiempo la Iglesia había acabado con la imprecisión doctrinal y fijado en siete el número de los sacramentos. Él dice que la investidura sólo puede ser otorgada por quien ya sea caballero, al igual que en la Iglesia nadie puede ordenar sin haber sido él mismo ordenado: "et este estado non puede aver ninguno por sí sy otri non gelo da, et por esto es commo manera de sacramento" (Cav., 18). En el código de las Partidas (II, XxI, 2) ya se señalaba que "non ha poder ninguno de fazer cavallero, sinon el que lo es", comparando igualmente este requisito con el que se da entre los "oradores".

Este carácter sacramental del ordo de la caballería significaba una tendencia hacia la sacralización del caballero, y una razón de primer rango para hacerlo ocupar un lugar privilegiado en la sociedad.

\section{b) Los deberes cristianos}

Ya desde el siglo $\mathrm{x}$, gracias a los esfuerzos de los monjes de Cluny, se había realizado la cristianización de la caballería como un estamento puesto al servicio de la communitas christiana, con lo cual se le había conferido un carácter semi-religioso de que carecía en sus orígenes. Es de notar que en la mayor parte de los códigos de caba-

27 Al principio, en la investidura del caballero sólo intervenían elementos de tipo militar, como la entrega de armas y una prueba de destreza y fuerza por parte del futuro caballero. Más tarde entraron elementos religiosos, con lo cual adquirió la ceremonia carácter cristiano y a la vez elegancia y delicadeza. Se comenzaba con la vela de armas, que no es sino la adaptación de las velaciones litúrgicas de Pascua y Pentecostés; al dia siguiente los aspirantes oían una misa y colocaban "la espada sobre el altar", ofreciéndola "a Dios e al altar". El sacerdote bendecía la espada, pero era un caballero quien se la ceñía al caballero novel y le daba el espaldarazo ("pescozada" en las Partidas). Para más detalles véase LÉon Gautier, op. cit., pp. 135 ss.

28 Cf. M. García Pelayo, el reino de Dios, p. 117. 
llería, que exaltan las virtudes del caballero, se hacen resaltar los deberes cristianos. Bonicio de Sutri, en su Liber de vita christiana (ca. 109o-95), establece como deberes específicos la lealtad y devoción al señor, la defensa de los pobres, viudas y huérfanos y la lucha contra los herejes ${ }^{29}$. Del mismo modo Juan de Salisbury (m. 1180), autor muy conocido en la época, codifica con la mayor exactitud los deberes del caballero, los cuales son "defender la Iglesia, acometer a los infieles, proteger a los pobres de las injurias, pacificar la provincia, dar su sangre por sus hermanos..."30; y las Partidas declaran que los defensores "han de defender la Iglesia, e los reyes, e todos los otros", y como virtud principal del caballero exigen la lealtad, de tal manera que "non dubd[en] de morir por su señor".

Como puede observarse, no hay una delimitación precisa entre la esfera laica y la religiosa, debido a ese aspecto tan típico de la Edad Media que es la interpenetración de lo religioso con todos los aspectos de la vida. Donde más expresamente se manifiesta esta interpenetración (dentro de nuestro tema) es en las órdenes militares, síntesis de vida monástica y militar. San Bernardo las juzga como el tipo ideal de caballería y las exalta en su tratado De la excelencia de la nueva milicia (1128), donde contrapone a la "malicia" del siglo, desprovista de todo fin justo, el nuevo género de milicia, "no conocido en los siglos pasados, en el cual se dan a un tiempo mismo dos combates. . , contra la carne y la sangre y contra los espíritus de malicia esparcidos en el aire"31. A los miembros de estas órdenes, San Bernardo los llama "caballeros de Jesucristo", "milicia de Dios", pues, en efecto, constituyen una congregación religiosa sujeta a regla monástica. Órdenes de este tipo, específicamente hispánicas como las de Santiago, Alcántara, Calatrava y Montesa, "que pueden aver cavallos et armas et usar dellas en servicio de Dios et defendimiento de la fe contra los moros", son citadas por Don Juan Manuel (Est., 2 a parte, 33 ).

En los caballeros, dentro de los estamentos laicos, se hacía más patente la dedicación sin reservas a la comunidad y a la defensa de la fe católica, y de allí partía en gran medida la estima y honra de que eran objeto: "la cavallería es más noble et más onrado estado que todos los otros; ca los cavalleros son para defender et defienden a los otros" (Cav., 18). A ello se unía la vida de peligros que llevaban, pues "non ay ninguno segund razón en que los omnes sean más aparejados para non bevir mucho commo en estado de cavallería, et esto por razón de los grandes trabajos et de los grandes peligros que ha en él, más que en ninguno otro estado" (Cav., 46).

29 Cit. por C. ERdmann, Die Entstehung des Kreuzzugsgedankens, Stuttgart, 1935 , p. 235 .

30 Policraticus, apud ERdmann, op. cit., p. 90.

31 Obras completas de San Bernardo $(B A C)$, Madrid, 1955, t. 2, p. 854 . 
c) Mártires de la fe

Natural era, debido a la ecuación entre servicio y privilegio a que hemos aludido más arriba, y a esa mezcla entre la dimensión religiosa y la política, que los caballeros recibiesen su premio por el alto servicio que prestaban a la comunidad cristiana, y que no sólo gozasen de estatuto jurídico privilegiado, sino que se considerasen mártires los que caían en defensa de la fe cristiana, idea que se generaliza en el Medioevo a partir de las Cruzadas. En el año de 1095, el Concilio de Clermont, convocado por Urbano II, había establecido la remisión de la penitencia impuesta por la Iglesia a los que cayeran en la cruzada, pero no la remisión de los pecados, aunque en muchos textos se habla de ella y de la entrada al paraíso; el mismo Papa, refiriéndose a España, amplía tal privilegio a los que participen en las guerras contra los moros: "ninguno que muera por Dios y sus hermanos en esta expedición debe dudar que le serán perdonados sus pecados y gozará de la vida eterna por la misericordia divina" 32 .

En Don Juan Manuel encontramos la misma idea de martirio: "todos los que van a la guerra de los moros et van en verdadera penitencia et con derecha entención, toviendo que pues [nuestro] señor Jesucristo murió por redimir los pecadores, que es de buena ventura si él muere en defendimiento et ensalzamiento de la sancta fe católica; et los que así mueren sin dubda ninguna son sanctos et derechos mártires" (Est., 76). Pero pone una salvedad, ya que no todos pueden ser santos y mártires según la recta doctrina canónica: es necesario "que vayan muy bien confesados et fecha emienda de sus pecados" (ibid.), y además con "derecha entención"33.

d) La. honra

El mantenimiento del prestigio del caballero y, en general, de toda la nobleza, unido a las exigencias que implicaba su preeminencia en la sociedad, en una palabra, el vivir noble, se basaba en la

32 Véase E. Kantorowicz, "Pro patria mori in medieval political thought", $A H R, 5^{6}$ (1951), $4^{80}$ ss. Una canción de cruzado, reproducida por Erdmann, op. cit., p. 317, dice así: "Illuc quicumque tenderit / mortuus ibi fuerit / caeli bona receperit / et cum sanctis permanserit". Esta idea persiste en el siglo xvi, y la encontramos por ejemplo en el Inca Garcilaso, Historia general del Perú, Segunda parte de los Comentarios reales de los Incas (Prólogo): “....afilarán sus azeros con nuevo brío y denuedo [los españoles]..., llevando adelante el buen nombre de su linaje, que parece traer su origen del cielo, adonde, como a patria propria y verdadera, deven caminar por este destierro... y, poniendo la mira en la corona de gloria que les espera, aspirar a llevársela, entrando por picas y lanças".

${ }^{33}$ En el Poema del Cid está presente la misma idea del perdón de los pecados para los que pelean contra los moros: "El que aquí muriere lidiando de cara / préndol yo los pecados, e Dios le abrá el alma" (vs. 1704-5). 
posesión de un hondo sentimiento del honor o, como dice Don Juan Manuel, de la honra, sin la cual la vida no tiene sentido y cuyo resorte es la vergüenza, que "le fará que sufra ante la muerte que fazer cosa vergoñosa” (Cav., 19).

No es éste el lugar para tratar el problema del sentimiento español del honor, que tanta importancia tendrá en el teatro clásico de los siglos xv1 y xv11. El problema que nos interesa aquí es determinar qué entienden Don Juan Manuel y su época por honra, y cuáles son las condiciones para su posesión. Ya las Partidas habían definido concisamente la honra: "Honra tanto quiere dezir como adelantamiento señalado con loor, que gana home por razón del logar que tiene o por fazer fecho conocido, o por bondat que en él ha" (II, xv11, 17). Es decir, la honra implica realzamiento, algo que sale de lo común y que, por tanto, es loado y respetado por la gente. Origen de la honra puede ser el estado o lugar social al que se pertenece (es, en este caso, una honra colectiva que irradia o se subjetiviza en cada uno de los miembros del estado o estrato social), un hecho famoso, y finalmente la posesión personal de buenas cualidades.

Análoga es la idea de Don Juan Manuel, para quien honra significa respeto, demostración de aprecio y estima, o reverencia: "la razón me da que como quier que el rey mio padre et yo ayamos mayor poder, et nos fagan las gentes mayor honra que a los otros..." (Est., 10); "pues Dios en estado de rey le pusiera, que tenido era del fazer honra et reverencia" (Est., 19); “et levólo el rey consigo, et fízol mucha honra et mucho bien" (Est., 21). Puede originarse en el rango social: "la primera dubda que yo tomo en la vida de los emperadores... es que yo veo que segunt los bienes que Dios les fizo et la honra en que los puso..., muy pocas vezes le pueden fazer aquel conoscimiento que deven" (Est., 56); "los parientes non son de un grado, nin son eguales en honra et en estado" (Est., 68). Y también puede originarse en la realización de grandes hechos ("la honra que deve ganar el cavallero por sus obras"), lo cual vendría a ser un aspecto más de la correlación entre privilegio y deber. Por último, el poder supone también honra, entendiéndose 'rico', 'riqueza' por poder y nobleza: "Mas quando dizen rico home, ponen la riqueza, que es honra, delante, et quiere dezir que es más honrado que las otras gentes, por los cavalleros que ha por vasallos et por el pendón que puede traer" (Est., 89).

De todo ello se sigue que la honra supone estima y respeto. Como ha dicho Taine: "En las clases medias e inferiores el motivo principal de la conducta es el interés propio. En la aristocracia, el resorte fundamental es el orgullo. Ahora bien, de todos los sentimientos profundos del hombre, ninguno es más capaz de transformarse en probidad, patriotismo y conciencia, pues el hombre orgulloso siente la necesidad de respetarse a sí mismo, y para lograr ese 
respeto se ve obligado a merecerlo" ${ }^{34}$. Estas palabras ponen de relieve que el orgullo parece ser condición del honor, y nos explican la vinculación entre ambos que se da en la forma de vida aristocrática. Pero para que los demás estimen la propia dignidad, es preciso comenzar por estimarla uno mismo. El mantenimiento de la honra implica una conducta de acuerdo con el propio status o dignidad. Así el Emperador debe hacer "mucha honra" a su mujer, "todavía guardando que non mengüe por ella ninguna cosa de su honra nin de las cosas que deve fazer" (Est., 66); y debe asimismo saber "fablar [de la guerra] guardando su honra et su pro" (Est., 57). Es preciso, además, no caer en lo contrario a la honra, es decir, en una situación afrentosa. De ahí la importancia que se da al sentimiento de la vergüenza, reiteradamente señalada por Don Juan Manuel como cualidad esencial del caballero, pues "es la cosa por que omne dexa de fazer todas las cosas que non deve fazer, et le faze fazer todo lo que deve. Et por ende, la madre et la cabeça de todas las vondades es la vergüença" (Cav., 19). La propia dignidad lleva, además, a no tolerar ofensas que aminoren la honra y hagan caer en la infamia, y asimismo a restaurar en caso necesario la honra dañada, incluso por la venganza.

En resumen, la honra exigía una conducta acorde con un patrón ético, independientemente de que su mantenimiento fuera o no ventajoso en lo material; una conducta ajustada a un principio que era preciso mantener más allá de todo cálculo de ventajas o inconvenientes. Ello se ve de modo patente en el caso de las guerras entre cristianos, que se suscitaban por la honra y se llevaban a cabo aunque la superioridad del enemigo fuese evidente y la derrota segura. Es cierto que la guerra entre los critianos es un mal, destructor de la concordia y la paz que debe existir entre los miembros de la cristiandad, pues la guerra, dice Don Juan Manuel, trae "deservicio de Dios. . . et mengua de derecho et de justicia" (Est., 7o). También es cierto que, por ello mismo, las guerras entre cristianos han de someterse a ciertos requisitos que las conviertan en una ejecución del derecho, más que en un acto político, señalando Don Juan Manuel como condición de guerra justa, por parte del que la hace, "que tenga derecho et que non la faga con tuerto nin con soberbia" (Est., 72) y, por parte del adversario, "grant culpa o merescimiento" (Est., 71). Así, pues, un señor cristiano "cada que pudiere aver paz con su honra, dévelo fazer et tomarla muy de grado" (Est., 70). Pero si bien existe un conjunto de condiciones que cumplir antes de empuñar justamente las armas, en cambio, la defensa de la propia honra tiene carácter incondicional. Ejemplo de esto es un hecho real de la vida del Infante, al cual se alude en el Libro de los esta-

${ }^{34}$ Cit. por J. Hulzinga, El otoño de la Edad Media, Madrid, 193o, t. 1, p. $9^{8}$. 
dos: la guerra que emprendió contra el rey de Castilla ${ }^{35}$. Los suyos le pedían "que fiziese alguna pleitesía porque saliese de aquella guerra, et don Johan dezía que fasta que oviese emienda del mal que recibiera et fincase con honra, que lo non faría; ca lo que le pasava con los suyos, o que perdía, o quanto mal le venía, que todo era daño o pérdida, mas non deshonra..., et que él se tenía por uno de los que eran para ser muertos mas non deshonrados" (Est., $\left.7^{\circ}\right)$.

e) La venganza

Pasemos ahora a otra faceta de la defensa de la integridad de la honra en su esencia y en sus accidentes o derechos. Los caballeros no pueden sufrir menoscabo de ninguna especie en la honra, y por eso "quando les alguno fiziere tuerto non gelo deven sofrir, ante se deven ende vengar lo más ayna que pudieren" (Cav., 46). Lo más pronto posible, porque es imposible vivir sin honra. Debemos guardarnos de dar a este vengarse el significado que tiene en el mundo actual; es preciso darle el que tenía en el mundo medieval, incluso en la etapa tardía en que escribe Don Juan Manuel. Observa Otto Brunner que en nuestro tiempo la venganza es una acción reprobable que sólo puede comprenderse y justificarse "bajo ciertas circunstancias", pero que "nos es completamente extraña como deber moral o jurídico"; en cambio, durante la Edad Media la venganza era un deber jurídico, de origen germánico ciertamente, pero pronto cristianizado hasta el punto de llegar a convertirse en la "venganza de Dios". La venganza, dice Brunner, no se limitaba a los hechos de sangre, sino a toda lesión del derecho; era exigencia del honor llevarla a cabo, y por tanto, "tolerar el entuerto renunciando a la venganza significaba una pérdida del honor". Brunner recoge una serie de testimonios literarios y jurídicos (incluso de origen imperial) de los siglos xiv y xv, para mostrar que se estimaba la venganza como contrapunto de la defensa del derecho y, por tanto, como exigencia del honor ${ }^{36}$.

Esta consideración de la venganza originada en el "derecho de estirpe" suponía un orden jurídico en el que cada persona tenía que velar por la defensa de su derecho (puesto que no era función del poder público), y en el que era lícita la guerra privada (Fehde), en

35 En 1325, Alfonso XI dio palabra de matrimonio a Constanza, hija de Don Juan Manuel; pero a los pocos años se casó con la hija del rey de Portugal. Don Juan Manuel, dispuesto a vengar la afrenta, se desnaturó del rey de Castilla y le declaró la guerra, aliándose con los moros. La guerra terminó con la intervención del obispo de Oviedo.

36 Otto Brunner, op. cit., pp. 21 ss. Véase también Hans Fehr, Die Tragik im Recht, Zürich, 1945, donde se hacen valiosas consideraciones sobre el deber jurídico de la venganza y se citan huellas de este deber todavía en el derecho suizo del siglo xvn. 
cuyo cuadro se enmarcaba la venganza. Aunque en la época de Don Juan Manuel las cosas habían cambiado, o comenzaban a cambiar, todavía se continuaba, tanto en España como fuera de ella, con los antiguos hábitos e ideas. Refiriéndose nuestro autor a la guerra, exalta la venganza: el que haga la guerra -dice- debe esforzar a los suyos e infundirles desprecio por los enemigos, "contándoles la razón del mal debdo que han con aquellos sus contrarios, et los tuertos que dellos han recibido, et quánto deven fazer por se vengar et por levar su honra adelante" (Est., 72), pues "los grandes homes que se mucho prescian et mucho valen son para seer muertos, mas non deshonrados" (Est., 70). Muestran estas palabras el profundo dramatismo que podía adquirir el sentimiento de la honra en la vida del hombre, y en la de toda una nación ${ }^{37}$.

\section{f) Educación y crianza}

Pertenecer plenamente a un estamento significaba adquirir, hasta fundirlas con la propia sangre, por así decir, unas determinadas formas de vida, más exigentes cuanto más alto era el estamento o el grado que se ocupaba dentro de él. Estas formas eran la configuración de un ethos, y se adquirían mediante una educación orientada, no tanto a la adquisición de conocimientos objetivos cuanto a la formación de una personalidad dotada de un sentimiento aristocrático, en el sentido originario de la palabra. La educación destinada a formar la personalidad se realizaba mostrando modelos o arquetipos del pasado y del presente, y de aquí que los libros educativos de la época tomaran el nombre de "espejos" o de "ejemplos". Dejando de lado los "Espejos de príncipes", es en el Libro de Patronio o Conde Lucanor donde la sabiduría práctica que representan los "ejemplos", como medio educativo modelador de toda una forma de vida, halla su más acabada expresión literaria. En el prólogo dice Don Juan Manuel que ha escrito su Libro de los exemplos "deseando que los homes feziesen en este mundo tales obras que les fuesen aprovechosas de las honras et de las faziendas et de sus estados, et fuesen más allegados a la carrera por que pudiesen salvar las ánimas". Palabras que reflejan claramente el fin ético-moral que buscaba tal tipo de educación.

Personificar las virtudes en determinadas figuras o modelos del pasado es típico de la Edad Media ${ }^{38}$. De ahí que se conceda gran

37 Cf. también Partidas, II, xıI, 4: “dos yerros son como eguales, matar a home et enfamarlo de mal; porque el home, después que es mal enfamado, maguer no haya culpa, muerto es quanto al bien et a la honra deste mundo; et demás tal podríe ser el enfamamiento, que mejor le serie la muerte que la vida". Estas ideas encontrarán su plena expresión en el teatro del Siglo de Oro.

38 Baste recordar el conocido pasaje de las Coplas de Jorge Manrique: "En ventura Octaviano; / Julio César en vencer / e batallar; / en la virtud, Affricano; / Hannibal en el saber / e trabajar", etc. 
importancia a la recitación de las hazañas heroicas. El buen caballero, "desque oviere comido et bebido, ... .a la mesa debe oír... juglares que le canten et tangan estormentes..., diziendo buenos cantares et buenas razones de cavallería et de buenos fechos que muevan los talantes de los que los oyeren para fazer bien" (Est., 59); y el capitán de un ejército debe contarles a sus gentes "muchas buenas fazañas de los reyes que fueron, et cómo por esfuerzo se vencen muchas lides de pocos a muchos..." (Est., 72). Esta costumbre de escuchar hechos heroicos durante la comida de los caballeros era usual en Castilla, y así dicen las Partidas que "acostumbravan los cavalleros, quando comían, que les leyesen las estorias de los grandes fechos de armas. ... e allí do no avían tales escrituras fazíanlo retraer a los caballeros buenos e ancianos que se en ellos acertaban" (II, XXI, 20).

Junto a esta educación estaba la crianza propiamente dicha, que podemos definir con palabras de Spengler como "el ritmo constante y armonía del contorno en que el sujeto vive, sintiéndolo, compenetrándose con él" ${ }^{39}$, y que se logra mediante la convivencia con los modelos del presente. Así, Don Juan Manuel hace decir al anciano caballero: "et commo quier que yo nunca leý nin aprendí ninguna sçiençia..., guareçí en casa de muchos señores [et] oý departir a muchos omnes sabios. Et bien cred que para los legos non ha tan buena escuela en el mundo cuemo criarse omne et bevir en casa de los señores" (Cav., 31). Como hemos dicho, el fundamento de todo este sistema radica en el valor que tiene el ejemplo como impulso primordial en la educación estamental, la cual procura formar, a diferencia de nuestra educación, que trata más bien de informar.

g) Ética estamental

El ethos que presidía a cada estamento sólo podía practicarse si se conocía. En las Partidas (IV, xxIII, 4), al tratar de los diferentes estados en que pueden vivir los hombres, se hace hincapié en el "muy grand pro" que trae "conocer e... saber el estado de los omes, porque mejor pueda ome departir, e librar lo que acaeciere en razón de las personas dellos". Se expresa así la diferencia de ética que había entre un estamento y otro. Por este motivo era primordial para una persona, según Don Juan Manuel, conocer su estado, para así saberlo guardar, pues "lo que pertenesçe al un estado es muy dañoso al otro" (Cav., 38). De acuerdo con la idea jerárquica, era tan contrario a la ética estamental aspirar a ascender como a descender de estado: "si el cavallero quisiere tomar estado de labrador o de menestral, mucho enpesçe al estado de cavallería, et esso mismo si estos dichos toman estado de cavallería" (ibid.).

$Y$ aun en el aspecto formal había una ética estamental que con-

39 O. Spengler, La decadencia de Occidente, Buenos Aires, 1952, t. 2, p. $43^{\circ}$. 
sistía en vivir de acuerdo con el propio estado: el varón de alto rango "deve guisar que ande él siempre vestido de paños mejores et más presciados que las otras gentes de su corte; et eso mesmo deve fazer en las bestias et en sus ensellamientos. .., [et] deve guardar que la su cama et la su bajiella... et las sus joyas... sean muy nobles et muy apuestas, segunt pertenesce al su estado" (Est., 62). Así como los grupos sociales estaban separados por sus funciones, por la honra, por los deberes, etc., también sus vestimentas lo estaban, como forma de delimitar visiblemente los estamentos.

\section{h) La riqueza}

Si a la honra de cada estado, como hemos visto, pertenecía vivir según la propia condición, debemos inferir que el pertenecer a estamentos superiores implicaba una mayor riqueza económica. Don Juan Manuel habla a menudo de la dificultad para mantener el "estado" cuando se tiene poco poder y riqueza, como es el caso de los infantes no herederos, que de suyo nada poseen, ya que todos los bienes pertenecen por sucesión al primogénito, pero que, por otra parte, tienen las obligaciones y deberes propios de su nobleza. No nos debe extrañar que Don Juan Manuel, hombre ambicioso que no escatima ningún medio para aumentar sus posesiones y mejorar su posición, y que vive en una época en que la antigua estructura agraria comienza a resquebrajarse ante el empuje de nuevas formas económicas que amenazan la vieja sociedad estamental, dé tanta importancia a la riqueza: "ca la bien andança et el poder et la riqueza faze seer a omne más amado et más preçiado de las gentes de quanto non sería si tan bien andante non fuesse". Tras lo cual añade, recordando quizá el agravio hecho en su hija: "muchos sirven et se fazen parientes del omne mientre [a] buena andança, que si la non oviere quel non catarían de los ojos si non topassen connél en la carrera" (Cav., 26).

La riqueza es en la sociedad estamental un instrumento que hace posible mantener la forma de vida del propio estado, pero no es factor de jerarquía social; bienes y condictio están en relación directa, siempre que en ello no haya el deleite y gusto por la riqueza como fin lucrativo, actitud repudiada por la ética social del tiempo: "el tesoro temporal de la Eglesia todo se deve espender en los pobres, et en defendimiento de la ley, et en las obras de misericordia... salvo ende lo que [el Papa] espendiere en su mantenimiento et en honra et en apostamiento de su estado; pero esto dévelo fazer por guardar su honra et su estado, mas non por deleite desordenado que en ello tome" (Est., $2^{\text {a }}$ parte, $3^{8}$ ).

Werner Sombart ha distinguido entre la "riqueza del poder", típica de la sociedad precapitalista, y el "poder de la riqueza", típico de la sociedad capitalista o de clases. En la primera, la riqueza sigue 
al poder; en la segunda, el poder sigue a la riqueza ${ }^{40}$. Es curioso y digno de señalarse que esta distinción se encuentra en el Infante cuando distingue entre "ricos homes" y "homes ricos". En el primer caso estamos en presencia de la riqueza en relación con el poder y honra del poseedor; en el segundo, la riqueza no denota "honra", puesto que decir "home rico" se entiende de cualquier hombre que tenga riqueza, "también ruano como mercadero", sin que ello lo califique de persona de honra y poder (Est., 89). Este segundo tipo de riqueza era, en principio, contradictorio con la lógica de la sociedad estamental, y, como hemos visto en un texto anteriormente citado, Don Juan Manuel se lamenta de la estima que comienza a concederse a la posición económica. Pero en sus textos nos muestra también el principio jerárquico tradicional que equilibraba status social y posición económica: los que son elevados a un estado superior engrosan al mismo tiempo su patrimonio. En el Libro del cavallero et del escudero, el escudero se convierte en caballero, adquiriendo así tierras y bienes, puesto que entre los deberes del rey está el "partir su aver" -como dice nuestro autor-con sus vasallos y naturales, tomando en cuenta el estado de cada uno y los servicios prestados en la guerra y en la administración del reino.

\section{i) Ruptura de la rigidez estamental}

Esto nos muestra ya cómo la rigidez de la sociedad estamental comenzaba a ser quebrantada por los problemas que planteaba la aparición de nuevas fuerzas en la realidad histórica, que, en el caso que hemos examinado, eran principalmente resultado del desarrollo de la economía monetaria. Pero había también otras exigencias que obligaban a adaptar a la realidad los cuadros de la sociedad estamental, y entre ellas cabe contar las necesidades planteadas por una organización más eficaz del gobierno político. Se ensancha, así, el estamento de los defensores hasta comprender dentro de su seno no sólo a los nobles defensores, sino también a los "homes que viven en las villas que non son homes fijos dalgo, nin viven por mercaduría nin por menesteres que fagan o que labren por sus manos..., et éstos son así como adalides, et almocadenes, et ballesteros, et otros homes de cavallo et de pie" (Est., 92), entre los cuales los de a pie o "peones" ocupaban un rango inferior (se puede considerar este grupo como una primera manifestación del soldado profesional no noble que rompe el monopolio militar de los caballeros); y entran asimismo en este estamento los "oficiales" (funcionarios), "que son del estado de los ruanos et de los mercadores, et dellos toman los señores algunos dellos seyendo moços et criados en sus casas, et por la buena crianza que han muchos dellos recuden muy buenos homes,

40 Werner Sombart, Der moderne Kapilalismus, München-Leipzig, 1919, t. 1, vol. 2, pp. 586 ss. 
et llegan a grandes honras et a muy grandes riquezas" y son llamados en Castilla "homes de criazón" (Est., 93). Es decir, que estos ruanos y mercaderes que originariamente pertenecían al estado de los labradores pasan en razón de su cargo o función al estado de los defensores.

Las diferencias de rango entre los pertenecientes al estamento de los defensores se manifiestan en la distribución de los cargos administrativos, ya que los nobles defensores ocupan los de mayor dignidad e importancia, como alcaldías, adelantamientos, merindades, etc., mientras que los homes de criazón son los oficiales que ponen los señores en sus casas. Entre esos cargos estaba el de recaudar las rentas e impuestos. A partir de 1286 se había logrado que la percepción de tales rentas no se encomendase a judíos, moros, nobles y eclesiásticos, quienes abusivamente podían cobrar cantidades distintas de las acordadas ${ }^{41}$. Seguramente Don Juan Manuel se refiere a este abuso por parte de los nobles cuando dice: "los homes de criazón et de las villas non se atreven a tanto como los nobles defensores, nin los señores non les deven catar tanta honra nin haver tan grand vergüença como a los nobles defensores, et puédenles tomar cuenta de lo que recabdan" (Est., 93). Pero el oficio más honrado que podían ocupar era el de canciller, que consistía en "tener los sellos del señor et mandar fazer las cartas todas", y "siempre los señores escogen tales chancelleres que sean sus criados o de sus padres, et que ayan con ellos muchos debdos para los servir" (Est., 95). Y lo reafirma en el Libro enfenido (cap. 11): "Otros oficiales ay que pueden ser fijos dalgo o omnes onrados, criados de los señores, así commo... chançeler et espensero... et todos los otros ofiçios de las casas de los señores que costunbran... de dar a sus criados". Nada mejor para aclarar el hecho de que el oficio de canciller, de tanta importancia, fuera dado a los homes de criazón, que remitirnos a Alfonso el Sabio, quien en las Partidas (II, Ix, 2) nos dice que los oficiales no deben ser "nin muy nobles, ni muy poderosos". Y lo explica: "de los nobles homes e poderosos non se puede el rey bien servir en los oficios de cada día; ca por la nobleza desdeñarían el servicio cotidiano; e por el poderío, atreverse ýen a fazer cosas que se tornaran en daño... Mas por esto debe tomar de los homes medianos". Los cargos menores en casa de los señores eran múltiples: físicos (médicos), despenseros, coperos, etc.

Así, la tendencia al hermetismo, nota esencial en la sociedad estamental, es contrarrestada por la inclusión de elementos de los estratos inferiores, con miras a la función que debían realizar, y que se insertan en el nuevo estado por la determinada educación que reciben y a través de la cual adquirían el ethos necesario a la nueva forma de vida que adaptaban. Si bien en los reinos cristianos de

41 Whadimiro Piskorski, Las cortes de Castilla, Barcelona, 1930, p. 167. 
España las clases sociales fueron más abiertas que en otras partes de Europa (especialmente en los primeros tiempos de la Reconquista, en que se ascendía con facilidad en jerarquía económico-social), ya para el siglo xiv, momento en que escribe Don Juan Manuel, los estamentos se encuentran más cerrados y estabilizados ${ }^{42}$. Y el hecho de que veamos en el estamento de los defensores a hombres de diferentes estratos no quiere decir que el paso de un estamento a otro fuera fácil. Desde luego, no afectaba a la estabilidad de la sociedad estamental, pues, como ha dicho Freyer, tal ascensión social, más que conmoverla la fortificaba, ya que los nuevos miembros del estamento sentían de modo más intenso, como es común a todo parvenu, el respeto hacia sus formas ${ }^{43}$.

\section{LABRADORES}

El último estado, el de los labradores, estaba constituido por todos aquellos que se dedicaban al trabajo de la tierra y a actividades relacionadas con ella. De ahí que se incluyan en el tercer estamento "los ruanos et los mercaderos", aunque "non son labradores", "porque la tierra se aprovecha dellos, porque los mercaderos compran et venden, et los ruanos fazen labrar la tierra, et dar ganados, et bestias. .. así como labradores" (Est., 93).

En realidad los ruanos y mercaderes constituían la incipiente burguesía del siglo xiv, que no llegó a cristalizar en España en una verdadera burguesía. Según García de Valdeavellano ${ }^{44}$, el nombre de ruanos se daba a los burgueses por razón de que vivían en las calles o rúas de las ciudades. La literatura medieval -agrega- desconocía a la burguesía como grupo social, y cuando aludía a ella la incluía en el estado de los labradores (así lo hace Don Juan Manuel), o eludía el problema, como en el caso de los menestrales o artesanos, a los cuales deja nuestro autor fuera del cuadro estamental. (Véase Est., 98).

Aparte de estas noticias, no se extiende mucho Don Juan Manuel sobre el grupo de los labradores. En primer lugar, lo consideraba un estado muy peligroso para salvar el alma -tema sobre el que gira el Libro de los estados-, "porque muchos déstos son menguados de entendimiento, que por torpedat podrían caer en grandes yerros non lo entendiendo" (Est., 98). Y en segundo lugar, lo desdeña por ser el estamento inferior de una sociedad dominada por el principio jerárquico. Así, concluye que "paresce mejor en los callar que

42 H. FREYER, Introd. a la sociologia, p. 156.

${ }_{43} \mathrm{El}$ proceso es común a toda Europa. El periodo que se extiende aproximadamente de 1250 a 1400 fue el de más rigurosa jerarquización de las capas sociales. Véase M. BLoch, La société féodale, II: Les classes et le gouvernement des hommes, Paris, 1940, p. 66.

${ }_{44}$ Sobre los burgos y los burgueses en la España medieval, Madrid, 1960, p. 22. 
en los poner en tal libro como éste" (ibid.), decisión en que lo acompañan otros escritores de la época ${ }^{45}$.

Unos pocos años separan a Don Juan Manuel del Arcipreste de Hita, y apenas una generación del canciller López de Ayala. Sus obras se enmarcan en un mismo siglo, el xıv; pero las diferencias en la visión que cada uno nos da de su tiempo y de su sociedad son mayores que los años que transcurren entre ellos.

Es Don Juan Manuel el que representa de modo más fiel el espíritu del hombre que pasa de la alta Edad Media a la baja, y más restringidamente el de una "clase" guerrera que reunía a la vez poder y riqueza. Fue de los hombres formados en la nobleza del espíritu de un pasado que se mantenía vivo; detrás de sí tenía un Rey Santo y un Rey Sabio, y una época de grandes hazañas en la que su clase era portadora de las virtudes que la llevaban a ser la cabeza de la sociedad. Para Don Juan Manuel aún se mantenía vigente el espíritu caballeresco que había animado a los hombres que realizaron la Reconquista. Ese espíritu, exaltado por él en el Libro del cavallero, todavía no se había convertido, como un poco más tarde, en puro juego de formas reducido a la vida de corte. Ya sentía, sin embargo, que la Castilla de su tiempo no poseía aquella honra que mantuvieron con sus gestas heroicas sus antepasados y que no recobrarían "fasta que Dios quiera que los castellanos enmienden sus vidas e fagan enmienda de sus pecados, para que pierda Dios saña de ellos".

Como representante de una clase orgullosa, segura de su poderío y de su significación, Don Juan Manuel no pudo o no quiso ver los cambios que se acercaban, aunque ya presentía con dolor la fuerza que iba adquiriendo el dinero, y que haría decir al espíritu burgués del Arcipreste (coplas 510-511):

El dinero del mundo es grand rrebolvedor:

señor faze del siervo, de señor servidor, toda cosa del siglo se faze por su amor.

Por dineros se muda el mundo e su manera, toda muger, codiçiosa del algo, es falaguera, por joyas e dineros salyrá de carrera:

el dinero quiebra peñas, fyende dura madera.

El Arcipreste se va a burlar de todo lo que era la tradición y las formas de vida de la Edad Media, y López de Ayala va a descubrir los

${ }_{45}$ Por ejemplo el cronista de la corte de Borgoña, Georges Chastellain (1405-1475), que dice: "Pour venir au tiers membre, qui fait le royaume entier, c'est l'estat des bonnes villes des marchans et des gens de labeur, desquels il ne convient faire si longue exposition que des autres, pour cause que de soy il n'est gaires capable de hautes attributions, parce qu'il est au degré servile" (cit. por J. HuizingA, op. cit., t. 1, p. 87). 
males de esa sociedad que ya no respondía a los principios que habían sido su fundamento. Pero Don Juan Manuel la captó tal como fue y como según él debía seguir siendo, dejando de lado lo accidental, que aún no trastornaba su cuadro estratificado y fijo.

Sería caer en ligereza creer que lo que trasladó a su obra no respondía a la realidad. En primer lugar, toda realidad histórica está formada por algo que todavía es y por algo que está en el curso del devenir, y tan constitutivo de la realidad es lo uno como lo otro. Dicho en otras palabras: el presente es el punto que vincula el pasado y el futuro, lo que todavía es pero que está en trance de no ser, y lo que todavía no es, pero está en trance de ser. En segundo lugar, nadie que contemple la realidad social puede tener frente a ella la imparcialidad del científico natural, pues el observador no está separado del objeto, sino que forma parte de él y tiene frente a sí una realidad vital que ha de ver desde una perspectiva también vital $\mathrm{y}$, por tanto, desde un determinado ángulo y alcanzando un determinado horizonte. Sólo integrando las distintas perspectivas podemos, quizá, obtener una visión vital del campo de estudio. Desde la perspectiva de su tiempo y de su vida, las obras de Don Juan Manuel nos recuerdan esos retablos medievales que unen a la sencillez ingenua grandes pasiones y cuyas figuras, agrupadas armónicamente, reflejan una concepción estática de la sociedad, que a la vez aparece como reflejo del orden divino.

Luciana de Stefano

Instituto de Filología "Andrés Bello",

Universidad Central de Venezuela. 